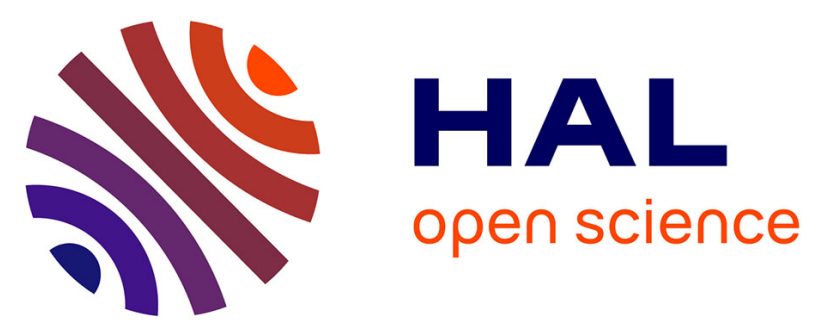

\title{
Superhydrophobic and luminescent highly porous nanostructured alumina monoliths modified with tris(8-hydroxyquinolinato)aluminium
}

Kh.E. Yorov, A.N. Khodan, A.E. Baranchikov, V.V. Utochnikova, N.P. Simonenko, A.N. Beltiukov, D.I. Petukhov, Andrei Kanaev, V.K. Ivanov

\section{To cite this version:}

Kh.E. Yorov, A.N. Khodan, A.E. Baranchikov, V.V. Utochnikova, N.P. Simonenko, et al.. Superhydrophobic and luminescent highly porous nanostructured alumina monoliths modified with tris(8-hydroxyquinolinato)aluminium. Microporous and Mesoporous Materials, 2020, 293, pp.109804. 10.1016/j.micromeso.2019.109804 . hal-02405797

\section{HAL Id: hal-02405797 https://hal.science/hal-02405797}

Submitted on 4 Jan 2021

HAL is a multi-disciplinary open access archive for the deposit and dissemination of scientific research documents, whether they are published or not. The documents may come from teaching and research institutions in France or abroad, or from public or private research centers.
L'archive ouverte pluridisciplinaire HAL, est destinée au dépôt et à la diffusion de documents scientifiques de niveau recherche, publiés ou non, émanant des établissements d'enseignement et de recherche français ou étrangers, des laboratoires publics ou privés. 


\title{
Superhydrophobic and luminescent highly porous nanostructured alumina monoliths modified with tris(8-hydroxyquinolinato)aluminium
}

\author{
Kh.E Yorov $^{a, b}$, A.N. Khodan ${ }^{c}$, A.E. Baranchikov ${ }^{a, b}$, V.V. Utochnikova ${ }^{a}$, \\ N.P. Simonenko ${ }^{b}$, A.N. Beltiukov ${ }^{d}$, A. Kanaev ${ }^{e}$, V.K. Ivanov ${ }^{b, f}$ \\ ${ }^{a}$ Lomonosov Moscow State University, Moscow, 119991, Russia \\ ${ }^{b}$ Kurnakov Institute of General and Inorganic Chemistry, Russian Academy of Sciences, \\ Moscow, 199071, Russia \\ ${ }^{c}$ Frumkin Institute of Physical Chemistry and Electrochemistry, Russian Academy of Sciences, \\ Moscow, 199071, Russia \\ ${ }^{d}$ Physical-Technical Institute of the Ural Branch of the Russian Academy of Sciences, Izhevsk, \\ 426000, Russia \\ ${ }^{e}$ Laboratoire des Sciences des Procédés et des Matériaux C.N.R.S., Institut Galilée, Université \\ Paris 13, Sorbonne Paris Cité, 93430 Villetaneuse, France \\ ${ }^{f}$ National Research Tomsk State University, Tomsk, 634050, Russia
}

\begin{abstract}
A straightforward and facile procedure for the fabrication of superhydrophobic luminescent 3D nanomaterials was developed. Chemical modification of ultra-lightweight highly porous nanostructured aluminum oxyhydroxide (NOA) monoliths in 8-hydroxyquinoline vapors resulted in the formation of tris(8-hydroxyquinoline)aluminum on the surface of NOA nanofibrils. The original shape and size of the initial NOA monolith and its internal 3D nanostructure were completely preserved during the modification. Surface modified NOA samples demonstrated intense green luminescence as well as superhydrophobicity, the water contact angle being $\sim 153^{\circ}$. Keywords: nanomaterials, mesoporous alumina, 3D nanostructure, 8-hydroxyquinoline, luminescent complexes, fluorescence, superhydrophobicity.
\end{abstract}

\section{Introduction}

Metal oxide aerogels and aerogel-like materials possessing very low density, high mesoporosity and thermal stability are materials that are almost completely ideal for a wide 
range of applications, including high-temperature thermal insulation, catalyst supports, absorption of heavy metal ions and pollution removal $[1,2]$.

Among other methods of aerogel-like materials production, controlled oxidation of metallic aluminium through the Al-Hg layer in humid air is truly a low-cost and facile method, leading to the formation of highly porous 3D monoliths consisting of nanofibrils of aluminium oxyhydroxides (NOA, $\mathrm{Al}_{2} \mathrm{O}_{3} \cdot n \mathrm{H}_{2} \mathrm{O}$ ) [3,4]. Additional functionalization of $\mathrm{NOA}$, which is typically achieved by the binding of various species on their surface, e.g., by the impregnation of NOA in a modifier solution, significantly extends their application [5-8]. By the impregnation techniques, metal and metal oxide nanoparticles [3,5,9-11], as well as carbon nanotubes [12], were immobilized in the matrix of pre-annealed NOA materials.

Immobilization of coordination compounds into porous matrices allows the obtaining of functional materials that are used as catalysts [13], sensors [14,15], in flat panel displays [16], as scintillators [17], lasers [18], etc. [19-21]. Tris(8-hydroxyquinoline)aluminium ( $\mathrm{AlQ}_{3}, \mathrm{Fig}$. S1) is presently considered as one of the most reliable emitting materials because of its excellent stability and luminescent properties [22,23]. Immobilization of the $\mathrm{AlQ}_{3}$ complex in porous matrices can serve as an alternative method for obtaining luminescent 3D materials for optical applications $[24,25]$.

A general method of covalent binding of metal complexes to the porous metal oxide network consists of obtaining alkoxysilyl-substituted metal complexes of the type $\left\{\left[(\mathrm{RO})_{3} \mathrm{Si}\left(\mathrm{CH}_{2}\right)_{\mathrm{n}} \mathrm{A}\right]_{\mathrm{x}} \mathrm{ML}_{\mathrm{m}}\right\}$ (where $\mathrm{A}$ is the donor group, such as $-\mathrm{NH}_{2},-\mathrm{SH}$, etc., $\mathrm{M}-$ metal and L - ligand), which during sol-gel processing are tethered to the oxide matrix through the $\left(\mathrm{CH}_{2}\right)_{\mathrm{n}} \mathrm{SiO}_{3 / 2}$ groups [26,27]. However, this method is multi-stage and time-consuming. In our previous study, we have developed a facile synthetic approach to $\mathrm{Al}_{2} \mathrm{O}_{3}$-based aerogels modified with $\mathrm{AlQ}_{3}$ [28]. The $\mathrm{AlQ}_{3}$ complex was formed after the addition of HQ during the sol-gel transition in an alcoholic solution of aluminium nitrate. This method allows one-stage immobilization of the luminescent $\mathrm{AlQ}_{3}$ complex in the $\mathrm{Al}_{2} \mathrm{O}_{3}$ aerogel matrix. Nevertheless, the use of a liquid-phase approach doesn't allow the immobilization of large amounts of complexes into an aerogel matrix, thus limiting the luminescence intensity of modified aerogels [28].

In this paper we propose a gas-phase approach to immobilizing the luminescent $\mathrm{AlQ}_{3}$ complex on the surface of aerogel-like highly porous 3D nanomaterial, consisting of aluminium oxyhydroxides nanofibrils (NOA), the preparation and properties of which were reported in detail by Khodan et al. [29-31]. Modification of NOA was conducted by treating as-prepared monolithic NOA material with HQ vapors in air. The interaction of the NOA surface with 8hydroxyquinoline vapor leads to the condensation of $-\mathrm{OH}$ groups of HQ molecules with the 
surface Al-OH groups, which eventually leads to the formation of surface-bound tris(8hydroxyquinolinate)aluminium $\left(\mathrm{AlQ}_{3}\right)$, providing the material with both hydrophobicity and intense luminescence.

\section{Materials and Methods}

\subsection{Materials}

The following reagents were used as starting materials: aluminium plate (OOO Lab-3, $>99.99 \%$ ), potassium hydroxide (Khimmed, A.C.S.), nitric acid (Khimmed, A.C.S.), mercury nitrate (Khimmed, A.C.S.), silver nitrate (Khimmed, A.C.S.), 8-hydroxyquinoline (HQ, Aldrich, $99+\%)$ and deionized water.

\subsection{Synthesis of NOA monoliths}

The monolithic NOA were obtained by the method described previously [30,32]. The details of the synthesis are presented in the supplementary information (Fig. S2). The process of aluminium oxyhydroxide synthesis is described by Equation 1:

$$
2(\mathrm{Hg} \cdot \mathrm{Al})_{\text {liq }}+n \mathrm{H}_{2} \mathrm{O}_{\text {gas }}+3 / 2 \mathrm{O}_{2} \rightarrow\left[\mathrm{Al}_{2} \mathrm{O}_{3} \cdot n \mathrm{H}_{2} \mathrm{O}\right]_{\mathrm{NOA}}+2(\mathrm{Hg})_{\text {liq }}
$$

The synthesis of the monoliths was carried out at a temperature of $25^{\circ} \mathrm{C}$ and $70 \%$ relative humidity. For the raw NOA monoliths obtained, the value of $n$ in (1) was about 3.6.

\subsection{Surface modification of monoliths}

The surface of NOA monoliths was chemically modified by the treatment with 8-hydroxyquinoline vapors, which made it possible to successfully immobilize the $\mathrm{AlQ}_{3}$ complex; the modified sample is hereafter designated as NOAQ. We used a simple way to obtain NOAQ materials (Fig. 1a): a required amount of HQ (a molar ratio HQ:Al $=1$ ) was placed at the bottom of the weighing bottle and covered with a piece of tracing paper with the block of raw NOA placed on top. The bottle was then closed and placed in an oven at $60^{\circ} \mathrm{C}$.

In the process of being modified with 8-hydroxyquinoline vapors, NOA samples maintain their monolithic appearance and acquire a yellow color, typical of the $\mathrm{AlQ}_{3}$ complex (Fig. $1 \mathrm{~b}$ ). The change in color of the sample begins with the surface layers and gradually spreads over the entire volume (Fig. S3). A temperature of $60^{\circ} \mathrm{C}$ is optimal for the modification of NOA in HQ vapors. Higher temperatures $\left(>70^{\circ} \mathrm{C}\right)$ lead to HQ melting $\left(\mathrm{T}_{\mathrm{mp}}(\mathrm{HQ})=75^{\circ} \mathrm{C}\right)$ and its penetration into the NOA monolith, which leads to inhomogeneous distribution of the complex in the material. 

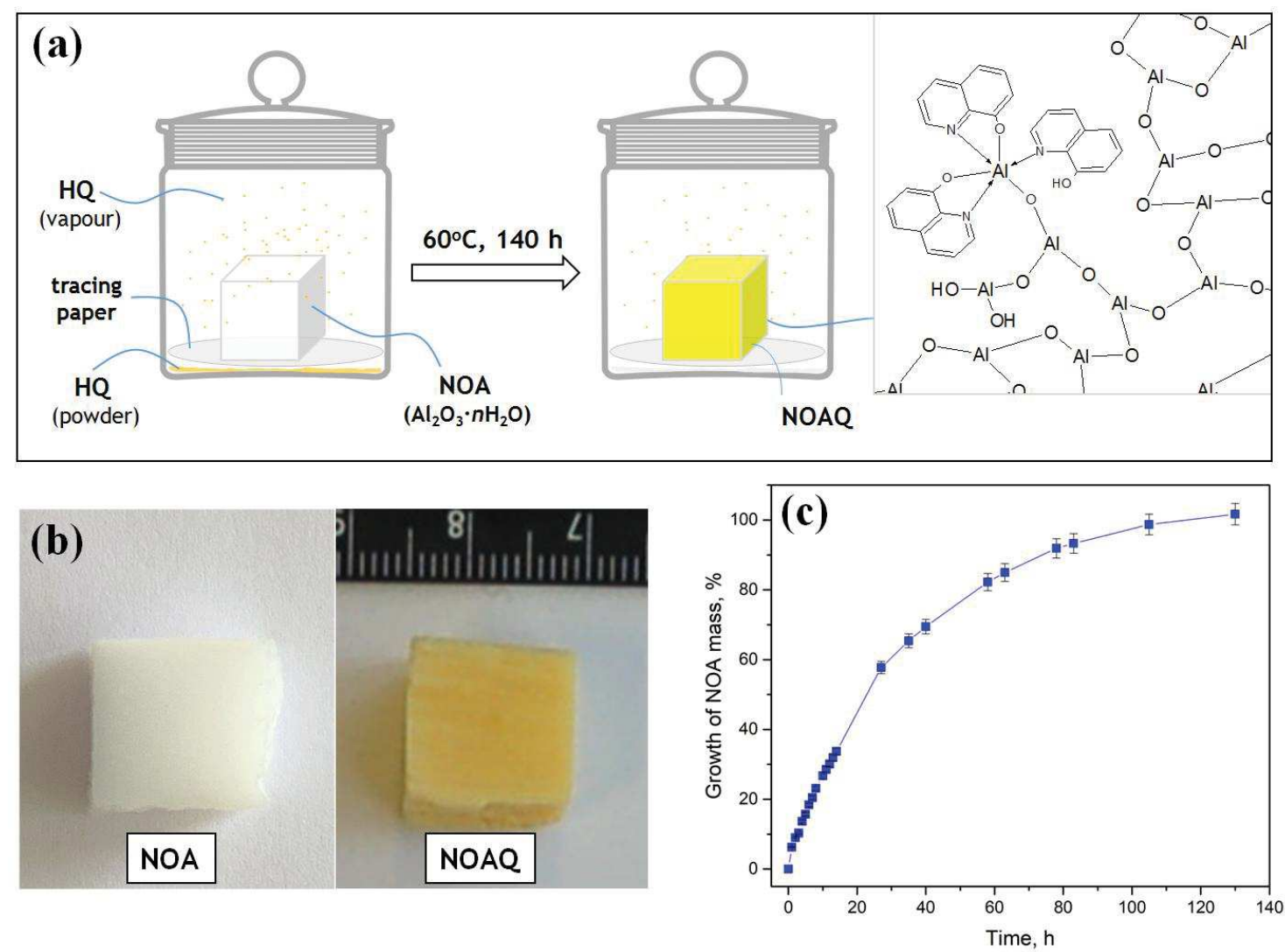

Fig. 1. (a) Scheme of the surface modification of NOA with 8-hydroxyquinoline; (b) a sample of NOA modified with 8-hydroxyquinoline; (c) the weight increase of NOA (in \%) during modification.

In order to determine the optimal duration of the NOA modification process, as well as the maximum amount of HQ adsorbed on the NOA surface, we measured the weight of NOA over time at a temperature of $60^{\circ} \mathrm{C}$ (Fig. 1c). For NOAQ samples with linear dimensions up to $\sim 2 \mathrm{~cm}$, the uniform coloration of the whole volume $\left(\mathrm{V} \leq 8 \mathrm{~cm}^{3}\right)$ was observed after $\sim 140$ hours of treatment. At that, the mass of the initial sample doubles. It is also worth noting that further treatment of the NOA monolith with HQ vapors leads to the crystallization of the latter on the surface of the monolith and the further increase of its weight.

\subsection{Methods of analysis}

The specific surface area $\left(\mathrm{S}_{\mathrm{BET}}\right)$ of NOA was measured by the low-temperature nitrogen adsorption method on a QuantaChrome Nova 4200B analyzer. Prior to analysis, the samples were degassed at $90^{\circ} \mathrm{C}$ in a vacuum for $17 \mathrm{~h}$. Based on the data obtained, the specific surface area of the samples was calculated using the Brunauer-Emmett-Teller model (BET) within the partial pressure range $0.07-0.25$. The calculation of the pore size distribution was carried out on the basis of nitrogen desorption isotherms, according to the Barrett-Joyner-Halenda method (BJH). 
The skeletal density of NOA was measured with a helium pycnometer, the Thermo Fisher Scientific Pycnomatic ATC.

The FTIR spectra of the samples were recorded using the attenuated total internal reflection technique (ATR) in the range $400-4000 \mathrm{~cm}^{-1}$ on a Perkin Elmer Spectrum 65 spectrophotometer equipped with a Quest ATR Accessory (Specac).

X-ray powder diffraction patterns were recorded with a Bruker D8 Advance diffractometer, using $\mathrm{CuK} \alpha$ radiation in the $2 \theta$ range $3-90^{\circ}$ at a $2 \theta$ step of $0.02^{\circ}$ and a counting time of $0.3 \mathrm{~s}$ per step.

The thermogravimetric analysis of NOA, as well as the identification of gaseous products evolved during thermal decomposition of the samples, was performed using a NETZSCH STA 409 PC Luxx synchronous thermal analyzer combined with a NETZSCH QMS 403 C Aëolos quadrupole mass spectrometer. The analysis was carried out in air at a heating rate of $10^{\circ} \mathrm{C} / \mathrm{min}$ to $800^{\circ} \mathrm{C}$.

The chemical composition of NOA samples was studied by X-ray photoelectron spectroscopy (XPS) on a SPECS X-ray photoelectron spectrometer with a PHOIBOS-150 energy analyzer at fixed analyzer transmission mode $(15 \mathrm{eV})$, using AlK $\alpha$ radiation $(\mathrm{hv}=1486.61 \mathrm{eV})$. Experimental data processing was performed with the CasaXPS software package.

The NOA morphology and structure were analyzed using a Carl Zeiss Libra 200 MC transmission electron microscope (TEM) operating at $200 \mathrm{kV}$, and a Carl Zeiss NVision 40 highresolution scanning electron microscope (SEM) equipped with an Oxford Instruments X-MAX $\left(80 \mathrm{~mm}^{2}\right)$ detector. SEM images were taken with an Everhart-Thornley detector (SE2) at $1 \mathrm{kV}$ accelerating voltage.

The water contact angles were measured with FTÅ200 (First Ten Angstroms, Inc., USA). The images were processed using FT 200 software.

The photoluminescence and excitation spectra were recorded on a Fluorolog spectrophotometer upon excitation with a xenon lamp. The quantum yield was measured on the same instrument, using a Quanta Phi integrating sphere.

\section{Results and discussion}

\subsection{Chemical composition of NOA and NOAQ}

To confirm the formation of the $\mathrm{AlQ}_{3}$ complex, as well as its immobilization on the alumina surface, the chemical composition of the NOA and NOAQ materials was analyzed using FTIR, XPS and TGA. Fig. 2 shows the FTIR spectra of 8-hydroxyquinoline, the NOAQ sample, and the $\mathrm{AlQ}_{3}$ complex. It should be noted that all the intense characteristic bands of the $\mathrm{AlQ}_{3}$ 
complex are present in the spectrum of the NOAQ sample. In particular, a maximum at 1327 $\mathrm{cm}^{-1}$, which belongs to the aromatic ring stretching, is present both in the spectrum of the $\mathrm{AlQ}_{3}$ complex and in the spectrum of the NOAQ sample, while it is not observed in the spectrum of pure 8-hydroxoquinoline. The band at $3400 \mathrm{~cm}^{-1}$ in the HQ spectrum (Fig. 2a) is assigned to O-H stretching vibrations. The broad absorption band at $3700-2800 \mathrm{~cm}^{-1}$ in the NOAQ spectrum is due to the vibrations of $\mathrm{O}-\mathrm{H}$ groups of both chemically bound and adsorbed water. The absence of a pronounced peak at $3400 \mathrm{~cm}^{-1}$ indicates the absence of free HQ molecules in NOAQ; chemical binding of $\mathrm{HQ}$ with the formation of the $\mathrm{AlQ}_{3}$ complex leads to the disappearance of this band in the spectrum of $\mathrm{AlQ}_{3}$ (Fig. 2c).

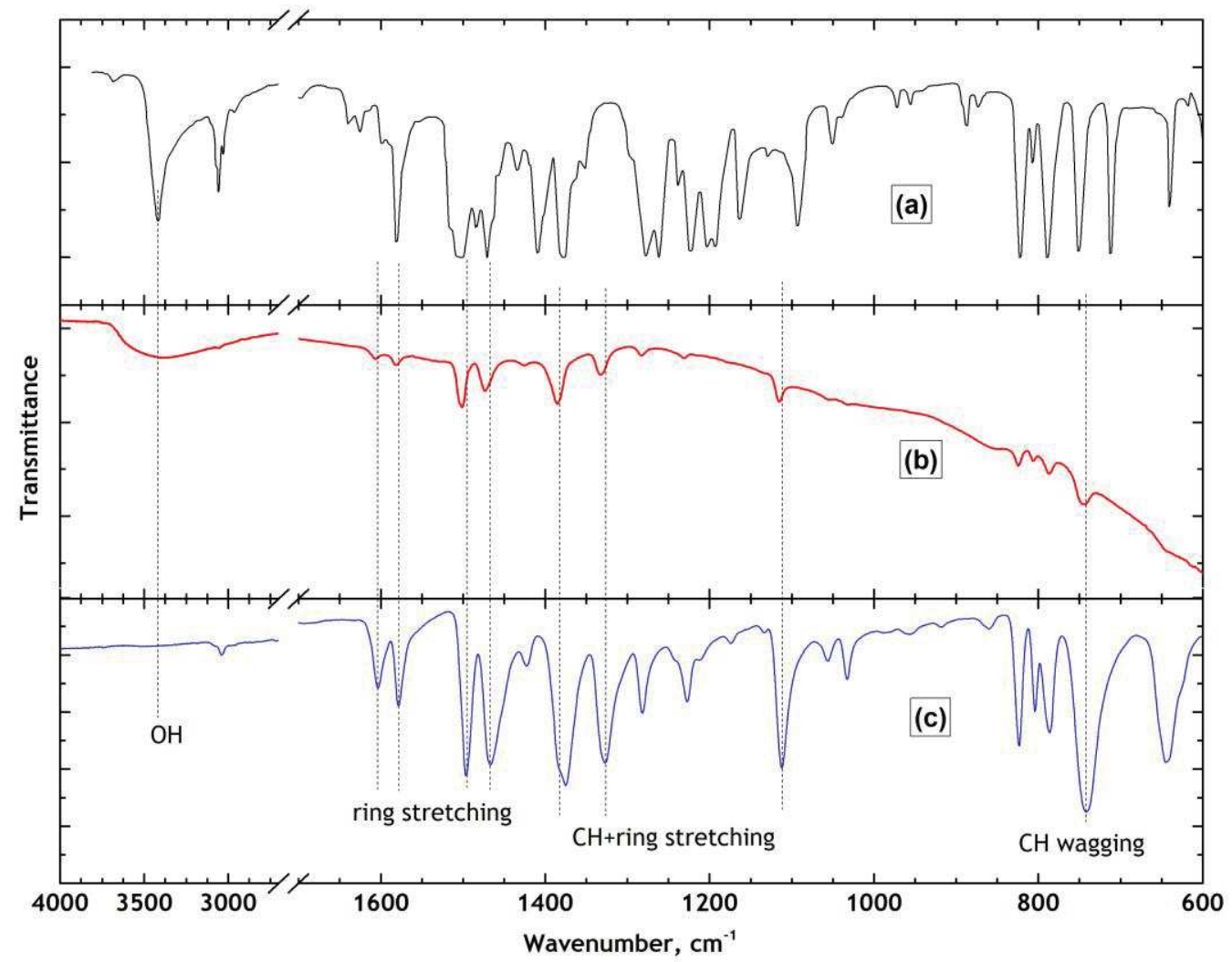

Fig. 2. IR spectra of 8-hydroxyquinoline (a), NOAQ sample (b), and the $\mathrm{AlQ}_{3}$ complex (c).

The presence of an $\mathrm{AlQ}_{3}$ complex on the surface of the NOAQ sample is also confirmed by the results of the XPS analysis; the position and shape of $\mathrm{N} 1 \mathrm{~s}$ and $\mathrm{C} 1 \mathrm{~s}$ lines for the NOAQ are similar to the $\mathrm{AlQ}_{3}$ (Fig. S4). Table S1 summarizes the element concentrations calculated using corresponding XPS spectra, which show that the C/N ratio in the NOAQ is quite close to the $\mathrm{C} / \mathrm{N}$ ratio in $\mathrm{AlQ}_{3}$.

Fig. S5 presents the diffraction patterns of NOA and NOAQ. Both materials are amorphous, but the position of the extremely broadened maxima suggests that the short-range order of atoms in the NOA structure is similar to the boehmite $\mathrm{AlO}(\mathrm{OH})$ structure [JCPDS 761871]. The treatment of NOA with 8-hydroxyquinoline does not affect its initial 3D structure. 
The results of TGA analysis of NOA and NOAQ materials combined with mass spectroscopy of gaseous thermolysis products are shown in Fig. 3. The TGA curve of the NOA contains one extended stage, while the thermal decomposition of NOAQ is more complex. Table 1 summarizes the temperature ranges and the corresponding weight loss for each stage of thermolysis.
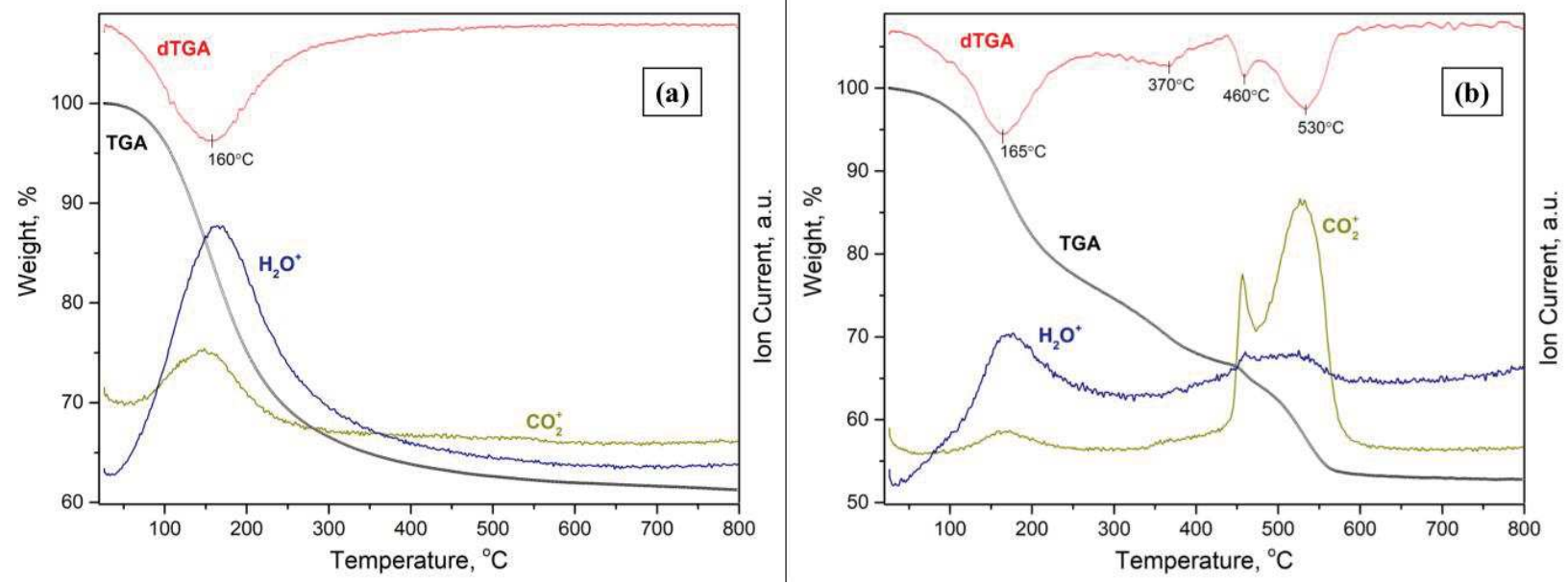

Fig. 3. The results of TGA combined with mass spectrometry of gaseous products of thermolysis, for the unmodified NOA (a) and for the chemically modified NOAQ (b). The mass number values $\mathrm{m} / \mathrm{z}$ are shown next to the corresponding temperature dependencies of the ion current.

Table 1. Temperature ranges and the corresponding weight loss for each stage of NOA and NOAQ thermolysis.

\begin{tabular}{ccccc}
\hline & \multicolumn{2}{c}{ NOA } & \multicolumn{2}{c}{ NOAQ } \\
\hline Stage & $\begin{array}{r}\text { Temperature } \\
\text { range, }{ }^{\circ} \mathrm{C}\end{array}$ & Weight loss, $\%$ & $\begin{array}{c}\text { Temperature } \\
\text { range, }{ }^{\circ} \mathrm{C}\end{array}$ & Weight loss, $\%$ \\
& $25-800$ & 38.7 & $25-280$ & 24.2 \\
$\mathbf{1}$ & - & - & $280-440$ & 9.1 \\
$\mathbf{2}$ & - & - & $440-480$ & 2.8 \\
$\mathbf{3}$ & - & - & $480-800$ & 11.1 \\
$\mathbf{4}$ & & $\mathbf{6 1 . 3}$ & $\mathbf{5 2 . 8}$ \\
\hline Residue, $\%$ &
\end{tabular}

The extended NOA thermolysis stage with a maximum rate at $160^{\circ} \mathrm{C}$ (dTGA curve in Fig. 3a) is due to the removal of physically and chemically bound water $(\mathrm{m} / \mathrm{z}=18)$. In addition, $\mathrm{CO}_{2}$ emission $(\mathrm{m} / \mathrm{z}=44)$ is also observed in the temperature range of $100-250^{\circ} \mathrm{C}$, which apparently corresponds to the removal of chemisorbed $\mathrm{CO}_{2}$ present on the NOA surface in the form of aluminium oxo- and hydroxycarbonates [33]. The presence of carbon in the NOA sample is also confirmed by elemental analysis data (Table S2) and XPS data (Table S1).

The thermogram of the NOAQ sample can be divided into four stages of weight loss. The first stage relates mainly to the removal of physically bound water, the second to the removal of chemisorbed water, as well as weakly bound $\mathrm{HQ}$ and $\mathrm{CO}_{2}$ molecules (see Fig. $3 \mathrm{a}$ and $3 \mathrm{~b}$ ). Stages 
3 and 4, obviously, correspond to the decomposition of the $\mathrm{AlQ}_{3}$ complex in NOAQ. A similar picture is observed during the decomposition of the pure $\mathrm{AlQ}_{3}$ complex (Fig. S6). The multistage character of the NOAQ sample thermolysis is probably due to the fact that 8 hydroxyquinoline on the surface of NOA may be in the form of mono-, bis- and tris-complexes.

The TGA data and elemental analysis allowed us to establish an approximate chemical composition of both the initial NOA $-\mathrm{Al}_{2} \mathrm{O}_{3} \cdot 3.5 \mathrm{H}_{2} \mathrm{O} \cdot 0.4 \mathrm{CO}_{2}$, and the modified NOAQ $\mathrm{Al}_{2} \mathrm{O}_{3} \cdot 1.1 \mathrm{H}_{2} \mathrm{O} \cdot 0.4 \mathrm{CO}_{2} \cdot 0.16 \mathrm{AlQ}_{3}$. Thus, the content of aluminium in the form of the $\mathrm{AlQ}_{3}$ complex in NOAQ is $\sim 7 \mathrm{~mol} \%$, which corresponds to a mass ratio of $\sim 30 \%$. Since the initial samples lose a significant amount of water in the process of chemical modification, it can be concluded that the chemical adsorption of 8-hydroxyquinoline takes place and the chemical composition of NOAQ is getting close to $\mathrm{AlO}(\mathrm{OH})$.

\subsection{Microstructure of NOA and NOAQ}

Due to the highly porous structure of NOA, a significant fraction of atoms is located on the surface of the fibrils, so that chemical modification of NOA may lead to a change in its microstructure. In order to study the changes in the microstructure of NOA during modification, we used the methods of low-temperature nitrogen adsorption, helium pycnometry, as well as electron microscopy (SEM and TEM) techniques. The results of the low-temperature nitrogen adsorption measurements of the porous structure of the NOA and NOAQ materials are shown in Fig. 4. The obtained adsorption/desorption isotherms belong to Type IV, according to the IUPAC classification, and are characterized by $\mathrm{H} 1$ type hysteresis typical of materials containing narrow open pores on both sides. A sharp increase in adsorption at $\mathrm{P} / \mathrm{P}_{0}>0.95$ indicates the presence of relatively large pores $(\mathrm{d}>50 \mathrm{~nm})$, which is confirmed by the data on the pore size distribution (see inset in Fig. 4). Table 2 summarizes the differences in texture characteristics of the NOA and NOAQ materials. 


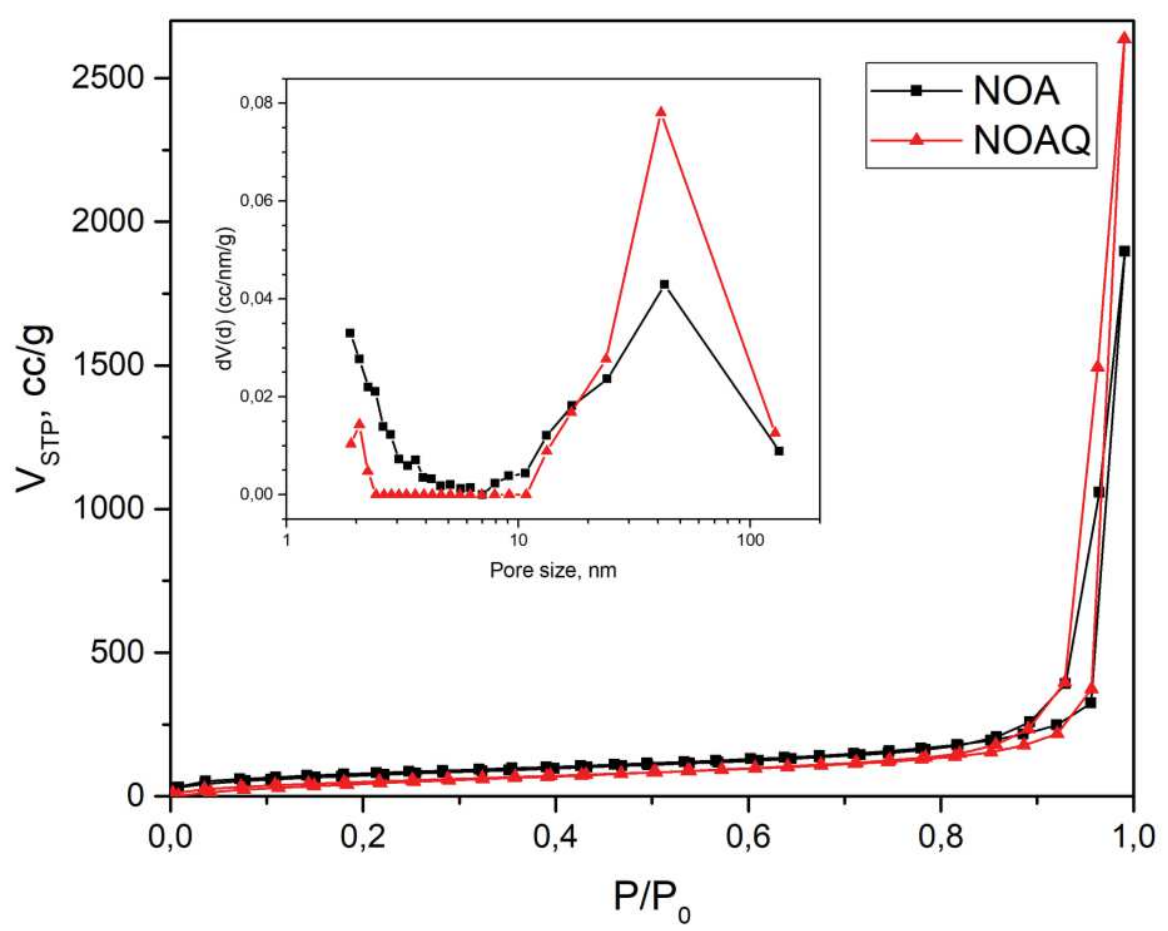

Fig. 4. Nitrogen adsorption/desorption isotherms and pore size distributions (inset) for NOA and NOAQ samples.

Table 2. Texture characteristics of NOA and NOAQ.

\begin{tabular}{lcc}
\hline & NOA & NOAQ \\
\hline Apparent density, ${\mathrm{g} \cdot \mathrm{cm}^{-3}}^{-3}$ & $0.018 \pm 0.005$ & $0.041 \pm 0.01$ \\
Skeletal density, $\mathrm{g} \cdot \mathrm{cm}^{-3}$ & $2.25 \pm 0.05$ & $2.63 \pm 0.10$ \\
Porosity, \% & $99 \pm 1$ & $98 \pm 1$ \\
Surface area, $\mathrm{m}^{2} \cdot \mathrm{g}^{-1}$ & $290 \pm 20$ & $205 \pm 10$ \\
Pore volume $\mathrm{cm}^{3} \cdot \mathrm{g}^{-1}$ & 2.95 & 4.20 \\
Average pore diameter, $\mathrm{nm}$ & 43 & 41 \\
BET constant $(\mathrm{C})$ & 66 & 23 \\
\hline
\end{tabular}

When the NOA surface is modified with 8-hydroxyquinoline, the monolithic appearance and initial sample sizes are preserved, the porosity remains almost unchanged, but the apparent density of NOAQ almost doubles in comparison with NOA, which can be explained by weight gain after substitution of the surface $-\mathrm{OH}$ groups and water molecules with heavier HQ molecules. The skeletal density also increases (Table 2). The adsorption of 8-hydroxyquinoline reduces the specific surface of the NOAQ sample, but the specific pore volume rises due to an increase in the number of large pores $(>20 \mathrm{~nm}$ ) (insert in Fig. 4). The decrease in the specific surface area can also be associated with an increase in the density of NOAQ, since the value of $\mathrm{S}_{\mathrm{BET}}$ is calculated per unit mass of the sample.

The initial structure of NOA samples can be described as a 3D network consisting of the nanofibrils of aluminium oxyhydroxides. The average size of the nanofibrils is about $5-7 \mathrm{~nm}$ in diameter, and the length is within $100-300 \mathrm{~nm}$ [30]. The studies of the NOA and NOAQ 
samples, carried out by electron microscopy, confirmed that after the NOAQ modification, the porous mesostructure remains almost unchanged (Figs. 5 and 6). However, by careful comparison of the morphology of the samples, slight coarsening and agglomeration of nanofibrils in NOAQ can be identified (Fig. 5).
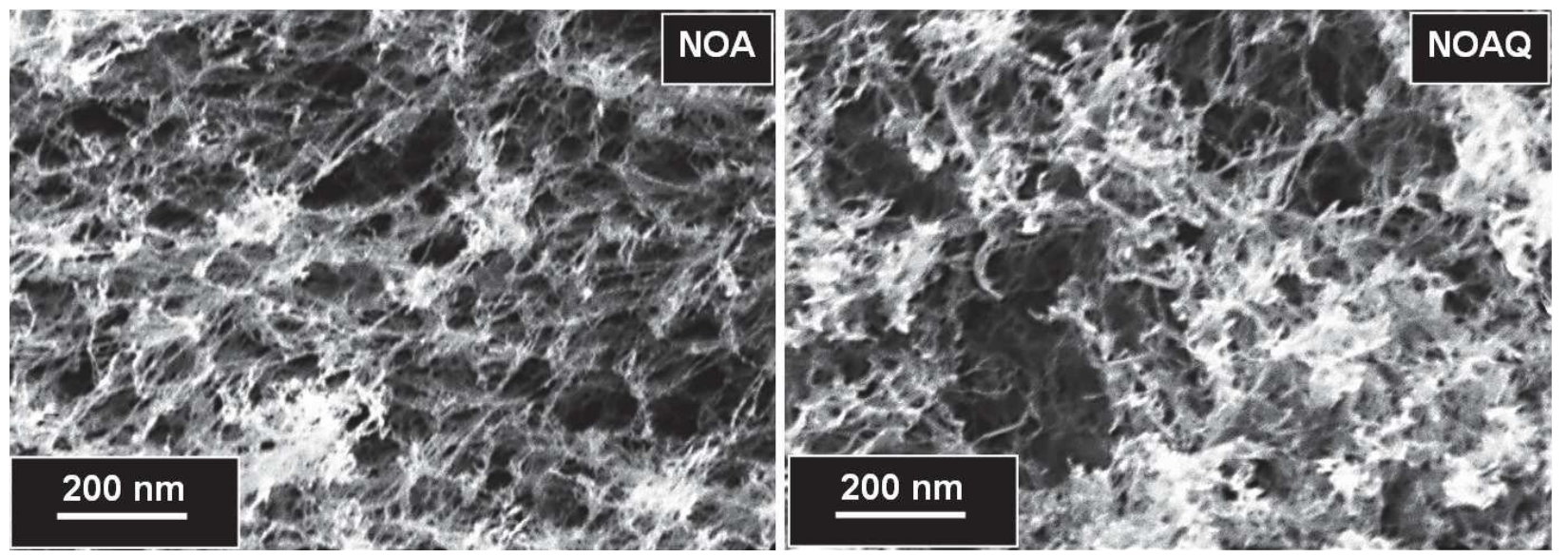

Fig. 5. SEM images of the NOA and NOAQ sample surface.

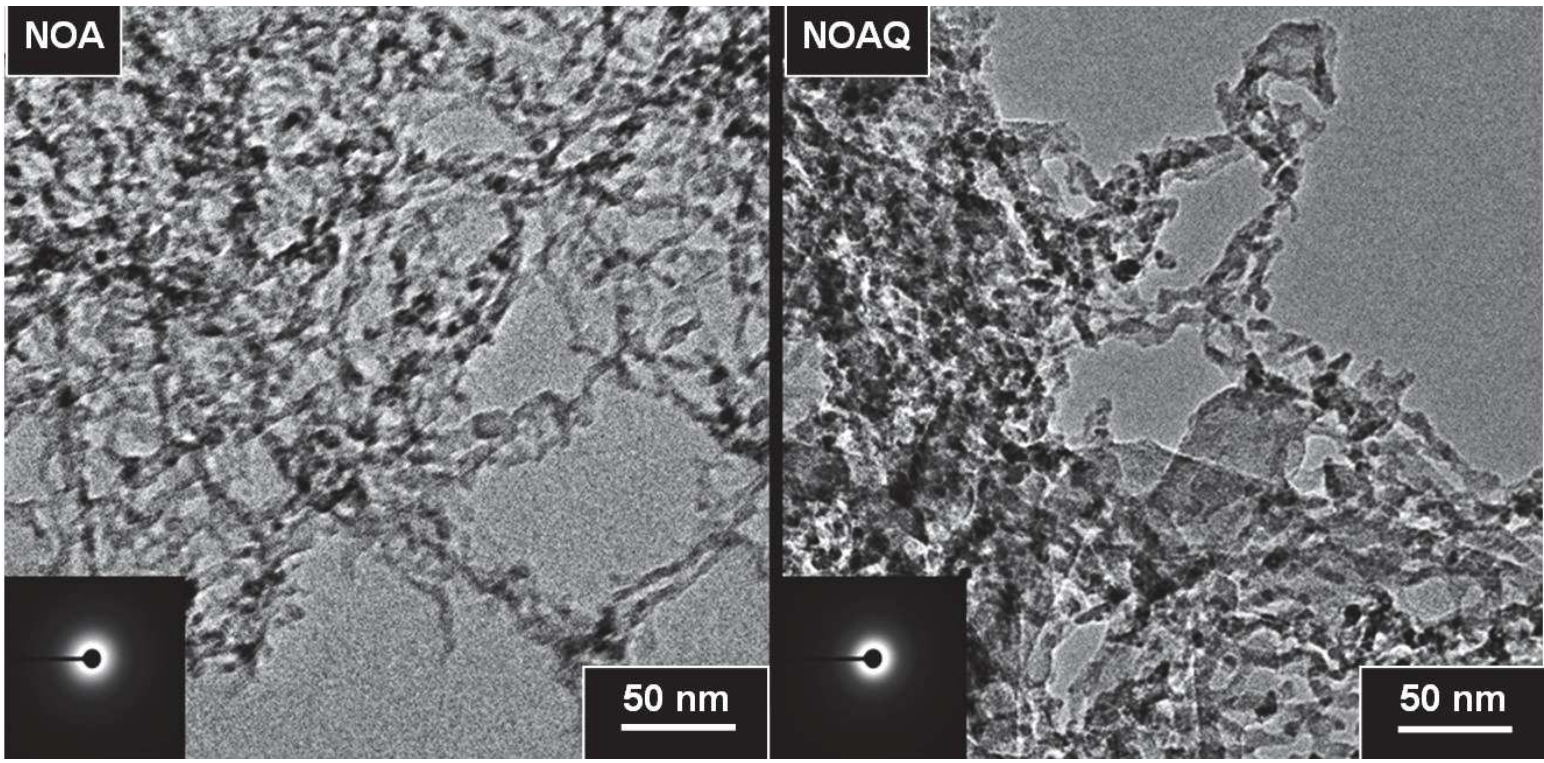

Fig. 6. TEM images of the NOA and NOAQ sample surface.

Fig. 6 shows the TEM images of the NOA and NOAQ samples with the insets of electron diffraction patterns. The structure of the samples can be described as a $3 \mathrm{D}$ grid of interweaved fibrils with almost the same diameter. Upon modification of the surface with 8hydroxyquinoline, the average size of the fibrils slightly increases (from $\sim 5 \mathrm{~nm}$ for the original NOA to $\sim 6-7 \mathrm{~nm}$ for NOAQ), which may be due to the formation of an $\mathrm{AlQ}_{3}$ layer on the surface of the fibrils. 


\subsection{Hydrophobicity of NOAQ}

The development of the hydrophobic properties of the NOAQ material was an unexpected effect of chemical surface modification with the $\mathrm{AlQ}_{3}$ complex. The raw $\mathrm{NOA}$ monoliths instantaneously collapse upon contact with water due to two reasons: 1) the presence of oxo and hydroxo-groups on the surface causes its hydrophilicity; and 2) high mesoporosity leads to water absorption due to capillary effects. NOA monoliths modified with 8hydroxyquinoline become hydrophobic and NOAQ samples float at the surface of water due to their low mass density (Fig. 7 and Fig. S7). A sufficiently large water contact angle $\left(\sim 153^{\circ}\right)$ allows us to classify this material as superhydrophobic.

It is obvious that the hydrophobicity of NOAQ is due to the weakly polar nature of the $\mathrm{AlQ}_{3}$ complex molecule, the layer of which covers the surface of fibrils in NOAQ. It should be noted that the very low solubility of $\mathrm{AlQ}_{3}$ in water $(\mathrm{pK}=32)$ is widely used in analytical chemistry for the quantitative determination of $\mathrm{Al}^{3+}$ ions [34]. At that, the rise of superhydrophobic properties is caused not only by the chemical nature of the surface, but also by its microstructure [35-37]. The roughness enhances the effect of the surface chemistry to produce the superhydrophobicity.

According to Wenzel's model [38]

$$
\cos \theta_{\mathrm{W}}=\mathrm{r} \cos \theta_{\mathrm{e}},
$$

where $\theta_{\mathrm{W}}-$ is the contact angle of a rough surface, $\theta_{\mathrm{e}}-$ is the contact angle of a flat surface (depending on the chemical nature of the surface) and $r$ - is the roughness ratio. One can see that small changes in $\theta_{\mathrm{e}}$ can lead to large changes in $\theta_{\mathrm{W}}$. In addition, according to equation (2), if angle $\theta_{\mathrm{e}}$ is less than $90^{\circ}$ then the surface roughness will lead to a decrease in $\theta_{\mathrm{W}}$ if angle $\theta_{\mathrm{e}}$ is more than $90^{\circ}$ it will lead to to an increase in $\theta_{\mathrm{W}}$.

Thus, the surface roughness of the NOA material leads to increased wettability or nonwettability of the surface, which in turn determines both the superhydrophobicity of the chemically modified NOAQ and the strong hydrophilicity of the raw NOA (Fig. S7). 


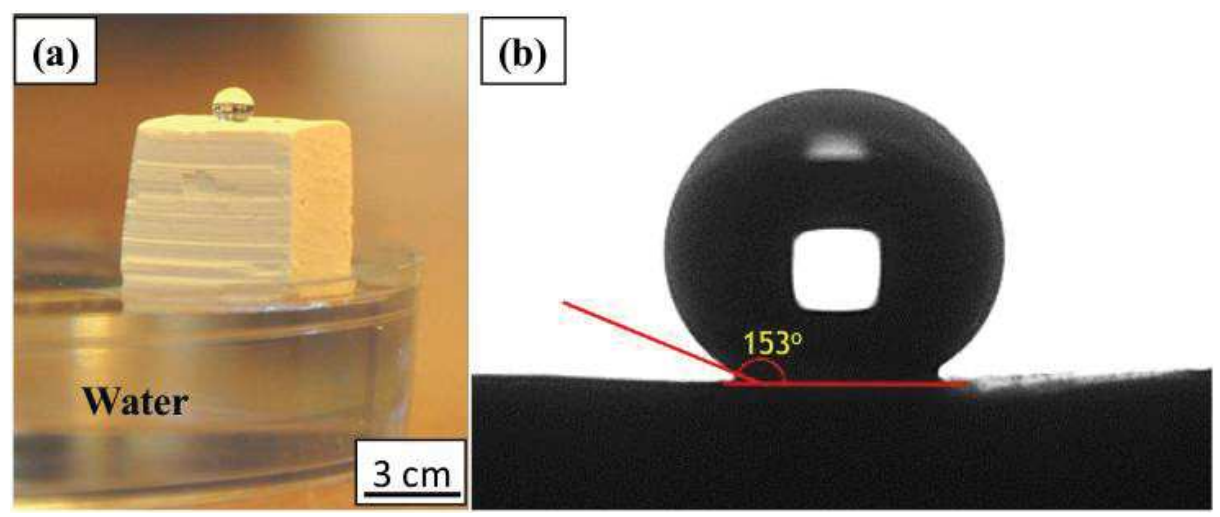

Fig. 7. Demonstration of hydrophobic properties after chemical surface modification of NOA samples with the $\mathrm{AlQ}_{3}$ complex: (a) a drop of water at the surface of the NOAQ sample (which also floats on the surface of water); (b) an estimation of the water contact angle.

In comparison to alumina-based aerogels modified with 8-hydroxyquinoline during the sol-gel transition [28], which demonstrate hydrophilic properties, NOAQ's hydrophobicity indicates that its entire surface is covered with a layer of $\mathrm{AlQ}_{3}$. Thus, the gas-phase modification has obvious advantages in comparison with the liquid-phase method. It should be noted that hydrophobicity greatly expands the range of applications of aerogels and aerogel-like materials, as their stability in a humid atmosphere is improved [39].

\subsection{Photoluminescent properties}

In order to clarify the state of the $\mathrm{AlQ}_{3}$ molecules in the pores, the photoluminescence spectra of the $\mathrm{AlQ}_{3}$ adsorbed on the surface of NOAQ were investigated. A comparison of the photoluminescent characteristics (Fig. 8 and S8) of NOAQ, NOA and $\mathrm{AlQ}_{3}$ also confirms the formation of the $\mathrm{AlQ}_{3}$ complex on the surface of NOAQ. Indeed, the luminescence spectrum of NOA (Fig. S8) does not contain any bands in the visible region as well as the excitation spectrum recorded at the luminescence wavelength of $550 \mathrm{~nm}$. In turn, NOAQ (Fig. 8) exhibits photoluminescence with a maximum at about $550 \mathrm{~nm}$, which corresponds to the luminescence spectrum of $\mathrm{AlQ}_{3}$. The excitation spectrum recorded at an emission wavelength of $550 \mathrm{~nm}$ coincides with the excitation spectrum of the $\mathrm{AlQ}_{3}$ complex. The luminescence quantum efficiency for the $\mathrm{AlQ}_{3}$ in NOAQ material is about $2 \%$, which is typical for $\mathrm{AlQ}_{3}$ in an amorphous state [40-42]. 


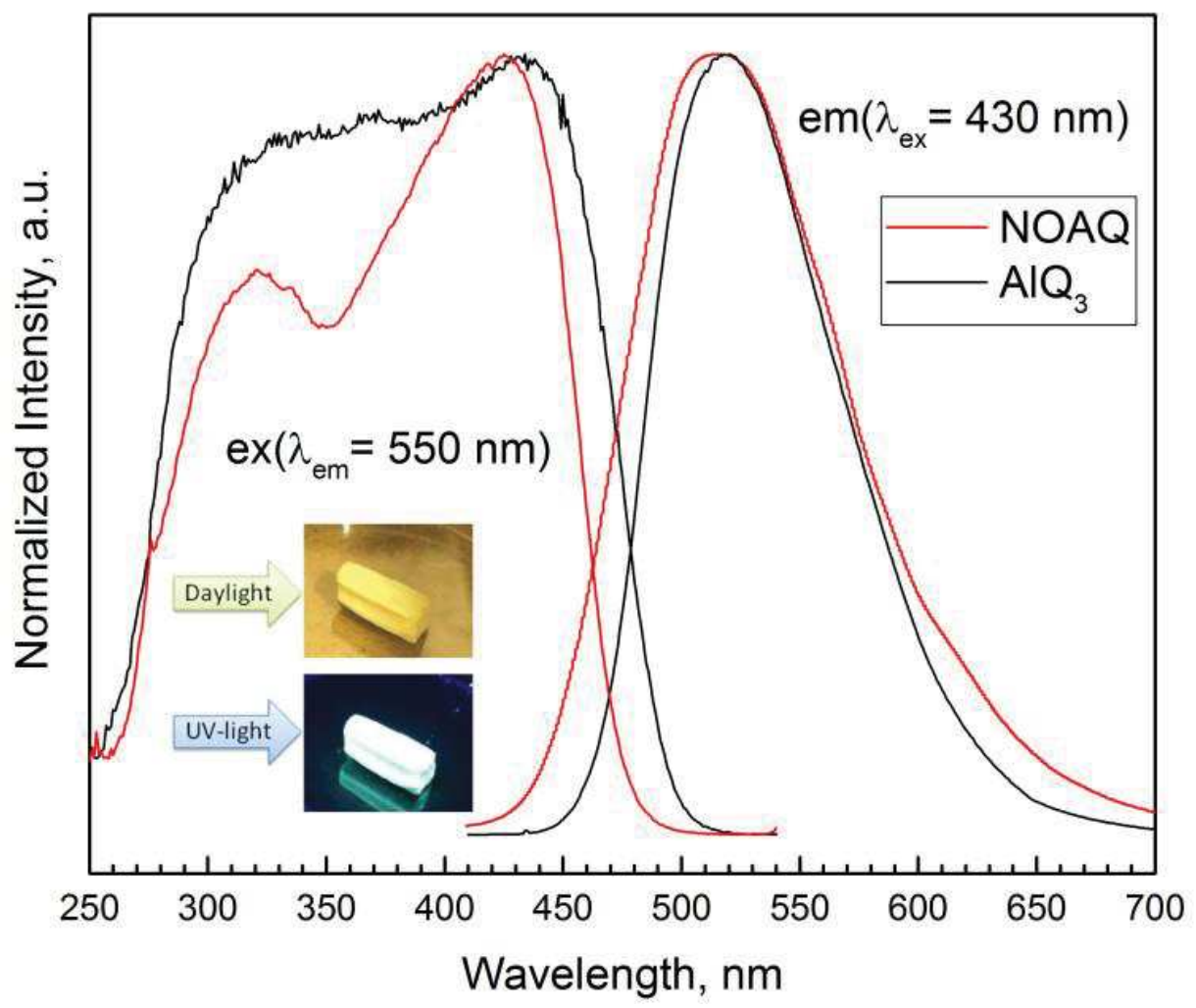

Fig. 8. Excitation and photoluminescence spectra at room temperature for the $\mathrm{AlQ}_{3}$ and $\mathrm{NOAQ}$. Excitation wavelength $=430 \mathrm{~nm}$, luminescence wavelength $=550 \mathrm{~nm}$; an inset represents the NOAQ monolith upon visible and UV-light $(\lambda=254 \mathrm{~nm})$ radiation.

One can see that for the NOAQ material, a blue-shift of the photoluminescence spectra is not observed (in comparison to the pure $\mathrm{AlQ}_{3}$ complex) as it is for other similar systems $[24,43-$ 47]. This is probably due to the high content of the complex in the pores of the NOAQ matrix, which makes its behavior close to the bulk $\mathrm{AlQ}_{3}$.

\section{Conclusions}

A method for the gas-phase surface modification of nanostructured porous aluminium oxyhydroxide monoliths with the luminescent tris(8-hydroxyquinolinato)aluminium complex was developed. It was shown that the original shape of the monolith is completely preserved after modification and its 3D nanostructure does not change significantly, retaining high porosity $(\sim 98 \%)$ and a high specific surface area $\left(\sim 250 \mathrm{~m}^{2} / \mathrm{g}\right)$. The modified NOAQ acquires superhydrophobic properties with the water contact angle $\sim 153^{\circ}$. Upon UV-irradiation, NOAQ porous monoliths show an intense luminescence in the green region of the spectrum $\left(\lambda_{\max }=550 \mathrm{~nm}\right)$. Thus, a multi-functional monolithic material possessing 3D nanostructure was obtained, combining high specific surface area, high porosity, low density, hydrophobicity and photoluminescent properties. 


\section{Acknowledgements}

The authors are grateful to V.A. Lebedev (Lomonosov Moscow State University) for assistance in conducting TEM measurements of the samples, K.V. Chaykun (Lomonosov Moscow State University) for assistance in conducting kinetic measurements, T.B. Khamova (Grebenshchikov Institute of Silicate Chemistry of the Russian Academy of Sciences, St. Petersburg, Russia) for assistance in BET measurements of the samples, I. A. Stenina (Kurnakov Institute of General and Inorganic Chemistry of the Russian Academy of Sciences, Moscow, Russia) for assistance in thermal analysis of the samples. This work was supported by the Russian Foundation for Basic Research (Project 17-53-150007 CNRS_a) and was partly supported by an IGIC RAS state assignment. Investigations were carried out using the equipment of the Joint Research Center for Physical Methods of Research of the Kurnakov Institute of General and Inorganic Chemistry of the Russian Academy of Sciences.

\section{References}

[1] N. Hüsing, U. Schubert, Aerogels-Airy Materials: Chemistry, Structure, and Properties, Angew. Chemie Int. Ed. 37 (1998) 22-45. doi:10.1002/1521-

3773(19980202)37:1/2<22::AID-ANIE22>3.3.CO;2-9.

[2] C. Ziegler, A. Wolf, W. Liu, A.K. Herrmann, N. Gaponik, A. Eychmüller, Modern Inorganic Aerogels, Angew. Chemie - Int. Ed. 56 (2017) 13200-13221.

doi:10.1002/anie.201611552.

[3] M. Bouslama, M.C. Amamra, Z. Jia, M. Ben Amar, K. Chhor, O. Brinza, M. Abderrabba, J.L. Vignes, A. Kanaev, Nanoparticulate TiO 2-Al $2 \mathrm{O} 3$ photocatalytic media: Effect of particle size and polymorphism on photocatalytic activity, ACS Catal. 2 (2012) 1884-1892. doi:10.1021/cs300033y.

[4] V.I. Mukhin, A.N. Khodan, M.M. Nazarov, A.P. Shkurinov, Study of the properties of nanostructured aluminum oxyhydroxide in the terahertz frequency range, Radiophys. Quantum Electron. 54 (2012) 591-599. doi:10.1007/s11141-012-9318-8.

[5] V. Logie, G. Maire, D. Michel, J.L. Vignes, Skeletal isomerization of hexenes on tungsten oxide supported on porous $\alpha$-alumina, J. Catal. 188 (1999) 90-101.

doi:10.1006/jcat.1999.2600.

[6] F. Di-Grégorio, V. Keller, T. Di-Costanzo, J.L. Vignes, D. Michel, G. Maire, Cracking and skeletal isomerization of hexenes on acidic MoO3-WO3/ $\alpha-\mathrm{Al} 2 \mathrm{O} 3$ oxide, Appl. Catal. A Gen. 218 (2001) 13-24. doi:10.1016/S0926-860X(01)00587-7.

[7] B. Zoellner, F. Hou, A. Carbone, W. Kiether, K. Markham, J. Cuomo, P.A. Maggard, Activating the Growth of High Surface Area Alumina Using a Liquid Galinstan Alloy, ACS Omega. 3 (2018) 16409-16415. doi:10.1021/acsomega.8b02442.

[8] A.G. Martynov, A. V. Bykov, Y.G. Gorbunova, A.N. Khodan, A.Y. Tsivadze, New Hybrid Materials Based on Nanostructured Aluminum Oxyhydroxide and Terbium(III) Bis(Tetra-15-Crown-5-Phthalocyaninate), Prot. Met. Phys. Chem. Surfaces. 54 (2018) 185191. doi:10.1134/S2070205118020090.

[9] T.D.C. L. Mazerolles, D. Michel, J.-L. Vignes, New Developments in nanometric porous mullite, spinel and aluminas, Ceram. Trans. 135 (2002) 227-239.

[10] Z.R. Huang, D. Jiang, D. Michel, L. Mazerolles, A. Ferrand, T. Di Costanzo, J.L. Vignes, Nickel-alumina nanocomposite powders prepared by novel in situ chemical 
reduction, J. Mater. Res. 17 (2002) 3177-3181. doi:10.1557/JMR.2002.0459.

[11] M. Bouslama, M.C. Amamra, O. Brinza, S. Tieng, K. Chhor, M. Abderrabba, J.L. Vignes, A. Kanaev, Isolation of titania nanoparticles in monolithic ultraporous alumina: Effect of nanoparticle aggregation on anatase phase stability and photocatalytic activity, Appl. Catal. A Gen. 402 (2011) 156-161. doi:10.1016/j.apcata.2011.05.042.

[12] J.B. Bai, J.L. Vignes, T. Fournier, D. Michel, A novel method for preparing preforms of porous alumina and carbon nanotubes by CVD, Adv. Eng. Mater. 4 (2002) $701-$ 703. doi:10.1002/1527-2648(20020916)4:9<701::AID-ADEM701>3.0.CO;2-T.

[13] E.F. Murphy, L. Schmid, T. Bürgi, M. Maciejewski, A. Baiker, D. Günther, M. Schneider, Nondestructive sol-gel immobilization of metal(salen) catalysts in silica aerogels and xerogels, Chem. Mater. 13 (2001) 1296-1304. doi:10.1021/cm001187w.

[14] N. Leventis, I.A. Elder, D.R. Rolison, M.L. Anderson, C.I. Merzbacher, Durable Modification of Silica Aerogel Monoliths with Fluorescent 2,7-Diazapyrenium Moieties.

Sensing Oxygen near the Speed of Open-Air Diffusion, Chem. Mater. 11 (1999) 2837-2845. doi:10.1021/cm9901966.

[15] J.E. Amonette, J. Matyáš, Functionalized silica aerogels for gas-phase purification, sensing, and catalysis: A review, Microporous Mesoporous Mater. 250 (2017) 100-119. doi:10.1016/j.micromeso.2017.04.055.

[16] S.A.C. Glauser, H.W.H. Lee, Luminescent Studies of Fluorescent ChromophoreDoped Silica Aerogels for Flat Panel Display Applications, MRS Proc. 471 (1997) 331. doi:10.1557/PROC-471-331.

[17] I.R. Boyko, M.A. Ignatenko, K. Esenak, L. Kuhta, J. Ruzička, V. Fainor, Scintillator based on SiO2-aerogel, Nucl. Inst. Methods Phys. Res. A. 363 (1995) 568-573. doi:10.1016/0168-9002(95)00228-6.

[18] R. Reisfeld, Prospects of sol-gel technology towards luminescent materials, Opt. Mater. (Amst). 16 (2001) 1-7. doi:10.1016/S0925-3467(00)00052-5.

[19] K. Binnemans, Lanthanide-Based Luminescent Hybrid Materials, Chem. Rev. 109 (2009) 4283-4374. doi:10.1021/cr8003983.

[20] K.E. Yorov, S.Y. Kottsov, A.E. Baranchikov, O. V. Boytsova, M.A. Kiskin, E.A. Varaksina, G.P. Kopitsa, S.A. Lermontov, A.A. Sidorov, V. Pipich, A. Len, A. V. Agafonov, V.K. Ivanov, Photoluminescent porous aerogel monoliths containing $\mathrm{ZnEu}$-complex: the first example of aerogel modified with a heteronuclear metal complex, J. Sol-Gel Sci. Technol. (2019) 1-15. doi:10.1007/s10971-019-04958-9.

[21] T.Y. Wei, C.Y. Kuo, Y.J. Hsu, S.Y. Lu, Y.C. Chang, Tin oxide nanocrystals embedded in silica aerogel: Photoluminescence and photocatalysis, Microporous Mesoporous Mater. 112 (2008) 580-588. doi:10.1016/j.micromeso.2007.10.040.

[22] C.W. Tang, S.A. VanSlyke, Organic electroluminescent diodes, Appl. Phys. Lett. 51 (1987) 913-915. doi:10.1063/1.98799.

[23] J.R. Sheats, H. Antoniadis, M. Hueschen, W. Leonard, J. Miller, R. Moon, D. Roitman, A. Stocking, Organic Electroluminescent Devices, Science (80-. ). 273 (1996) 884888. doi:10.1126/science.273.5277.884.

[24] S. Yamaguchi, K. Matsui, Formation and entrapment of tris(8hydroxyquinoline)aluminum from 8-hydroxyquinoline in anodic porous alumina, Materials (Basel). 9 (2016) 715. doi:10.3390/ma9090715.

[25] M. Tagaya, K. Shinozaki, Y. Maruko, A Simple Incorporation Route of Tris(8hydroxyquinoline)aluminum(III) into Transparent Mesoporous Silica Films and Their Photofunctions, J. Appl. Chem. 2017 (2017) 1-10. doi:10.1155/2017/7351263.

[26] U. Schubert, Sol-Gel Processing of Alkoxysilyl-Substituted Metal Complexes, Elsevier Inc., 2016. doi:10.1016/B978-0-12-803530-6.00034-2.

[27] G. Trimmel, C. Lembacher, G. Kickelbick, U. Schubert, Sol-gel processing of alkoxysilyl-substituted nickel complexes for the preparation of highly dispersed nickel in silicaElectronic supplementary information (ESI) available: Tables S1-S5 giving additional 
analytical data as described in the text and the ex, New J. Chem. 26 (2002) 759-765. doi:10.1039/b110612k.

[28] K.E. Yorov, A.D. Yapryntsev, A.E. Baranchikov, T. V. Khamova, E.A. Straumal, S.A. Lermontov, V.K. Ivanov, Luminescent alumina-based aerogels modified with tris(8hydroxyquinolinato)aluminum, J. Sol-Gel Sci. Technol. 86 (2018) 400-409. doi:10.1007/s10971-018-4647-5.

[29] T. di Costanzo, A.A. Fomkin, C. Frappart, A.N. Khodan, D.G. Kuznetsov, L. Mazerolles, D. Michel, A.A. Minaev, V.A. Sinitsin, J.L. Vignes, New Method of Porous Oxide Synthesis: Alumina and Alumina Based Compounds, Mater. Sci. Forum. 453-454 (2004) 315-322. doi:10.4028/www.scientific.net/MSF.453-454.315.

[30] A. Khodan, T.H.N. Nguyen, M. Esaulkov, M.R. Kiselev, M. Amamra, J.L. Vignes, A. Kanaev, Porous monoliths consisting of aluminum oxyhydroxide nanofibrils: 3D structure, chemical composition, and phase transformations in the temperature range 25$1700{ }^{\circ}$ C, J. Nanoparticle Res. 20 (2018) 194. doi:10.1007/s11051-018-4285-4.

[31] A.N.N. Khodan, G.P.P. Kopitsa, K.E.K.E. Yorov, A.E.E. Baranchikov, V.K.K. Ivanov, A. Feoktystov, V. Pipich, Structural Analysis of Aluminum Oxyhydroxide Aerogel by Small Angle X-Ray Scattering, J. Surf. Investig. X-Ray, Synchrotron Neutron Tech. 12 (2018) 296-305. doi:10.1134/s102745101802026x.

[32] J.-L.L. Vignes, C. Frappart, T. Di Costanzo, J.-C.C. Rouchaud, L. Mazerolles, D. Michel, Ultraporous monoliths of alumina prepared at room temperature by aluminium oxidation, J. Mater. Sci. 43 (2008) 1234-1240. doi:10.1007/s10853-007-2260-z.

[33] C.C. Ma, X.X. Zhou, X. Xu, T. Zhu, Synthesis and thermal decomposition of ammonium aluminum carbonate hydroxide (AACH), Mater. Chem. Phys. 72 (2001) 374 379. doi:10.1016/S0254-0584(01)00313-3.

[34] G.H. Jeffery, J. Bassett, J. Mendham, R.C. Denney, Vogel's Textbook of Quantitative Chemical Analysis, New York. 5th (1989) 696. doi:10.1016/01609327(90)90087-8.

[35] N.J. Shirtcliffe, G. McHale, S. Atherton, M.I. Newton, An introduction to superhydrophobicity, Adv. Colloid Interface Sci. 161 (2010) 124-138. doi:10.1016/j.cis.2009.11.001.

[36] S.A. Lermontov, N.A. Sipyagina, A.N. Malkova, A.E. Baranchikov, K.E. Erov, D.I. Petukhov, V.K. Ivanov, Methyltrimethoxysilane-based elastic aerogels: Effects of the supercritical medium on structure-sensitive properties, Russ. J. Inorg. Chem. 60 (2015) 488492. doi:10.1134/s0036023615040117.

[37] S.D. Bhagat, Y.H. Kim, K.H. Suh, Y.S. Ahn, J.G. Yeo, J.H. Han, Superhydrophobic silica aerogel powders with simultaneous surface modification, solvent exchange and sodium ion removal from hydrogels, Microporous Mesoporous Mater. 112 (2008) 504-509. doi:10.1016/j.micromeso.2007.10.030.

[38] R.N. Wenzel, Resistance of solid surfaces to wetting by water, Ind. Eng. Chem. 28 (1936) 988-994. doi:10.1021/ie50320a024.

[39] A.M. Anderson, M.K. Carroll, Hydrophobic Silica Aerogels: Review of Synthesis, Properties and Applications, in: Aerogels Handb., Springer New York, New York, NY, 2011: pp. 47-77. doi:10.1007/978-1-4419-7589-8_3.

[40] M. Cölle, J. Gmeiner, W. Milius, H. Hillebrecht, W. Brütting, Preparation and Characterization of Blue-Luminescent Tris(8-hydroxyquinoline)-aluminum (Alq3), Adv. Funct. Mater. 13 (2003) 108-112. doi:10.1002/adfm.200390015.

[41] I. Sokolik, R. Priestley, A.D. Walser, R. Dorsinville, C.W. Tang, Bimolecular reactions of singlet excitons in tris(8-hydroxyquinoline) aluminum, Appl. Phys. Lett. 69 (1996) 4168-4170. doi:10.1063/1.116974.

[42] W. Chen, Q. Peng, Y. Li, Alq 3 Nanorods: Promising Building Blocks for Optical Devices, Adv. Mater. 20 (2008) 2747-2750. doi:10.1002/adma.200702809.

[43] C. Xu, Q. Xue, L. Ba, B. Zhao, N. Gu, Y. Cui, Spectral behavior of 8- 
hydroxyquinoline aluminum in nanometer-sized holes of porous alumina, Chinese Sci. Bull. 46 (2001) 1839-1841. doi:10.1007/BF02900564.

[44] G.S. Huang, X.L. Wu, Y. Xie, F. Kong, Z.Y. Zhang, G.G. Siu, P.K. Chu, Photoluminescence from 8-hydroxy quinoline aluminum embedded in porous anodic alumina membrane, Appl. Phys. Lett. 87 (2005) 1-3. doi:10.1063/1.2099522.

[45] A. Mohammadpour, I. Utkin, S.C. Bodepudi, P. Kar, R. Fedosejevs, S. Pramanik, K. Shankar, Photophysics and Energy Transfer Studies of Alq $<$ SUB $>3</$ SUB $>$ Confined in the Voids of Nanoporous Anodic Alumina, J. Nanosci. Nanotechnol. 13 (2013) 2647-2655. doi:10.1166/jnn.2013.7348.

[46] L.L. Kong, B. Yan, Y.J. Li, Y. Li, Photoactive metallic (A13+, Zn2+, Eu3+, Tb3+, $\mathrm{Er} 3+, \mathrm{Nd} 3+$ ) mesoporous hybrid materials by functionalized 8-hydroxyquinolinate linkage covalently bonded SBA-15, Microporous Mesoporous Mater. 135 (2010) 45-50. doi:10.1016/j.micromeso.2010.06.009.

[47] C. Xu, Q. Xue, Y. Zhong, Y. Cui, L. Ba, B. Zhao, N. Gu, Photoluminescent blueshift of organic molecules in nanometre pores, Nanotechnology. 13 (2002) 47-50.

doi:10.1088/0957-4484/13/1/310. 